\begin{tabular}{|c|l|}
\hline Title & Transition of solidification mode and the as cast $y$ grain structure in hy perperitectic carbon steels \\
\hline Author(s) & Tsuchiya, Shingo; Ohno, Munekazu; Matsuura, Kiyotaka \\
\hline Citation & $\begin{array}{l}\text { Acta Materialia, 60(6-7), 2927-2938 } \\
\text { https://doi.org/10.1016/.actamat.2012.01.056 }\end{array}$ \\
\hline Issue Date & 2012-04 \\
\hline Doc URL & http://hdl.handle.net/2115/49358 \\
\hline Type & article(author version) \\
\hline File Information & AM60-6-7_2927-2938.pdf \\
\hline
\end{tabular}

Instructions for use 


\title{
Transition of solidification mode and the as-cast $\gamma$ grain structure in hyperperitectic carbon steels
}

\author{
Shingo Tsuchiya ${ }^{\text {a }}$, Munekazu Ohno ${ }^{\text {b, * }}$, Kiyotaka Matsuura ${ }^{\text {b }}$ \\ ${ }^{a}$ Graduate School of Engineering, Hokkaido University \\ ${ }^{\mathrm{b}}$ Division of Materials Science and Engineering, Faculty of Engineering, Hokkaido University, Kita \\ 13 Nishi 8, Kita-ku, Sapporo, Hokkaido 060-8628, Japan \\ * Corresponding author. Address: Division of Materials Science and Engineering, Faculty of \\ Engineering, Hokkaido University, Kita 13 Nishi 8, Sapporo, Hokkaido, 060-8628, Japan. Tel/fax: \\ +81 11706 6344. E-mail address: mohno@eng.hokudai.ac.jp
}

\begin{abstract}
Formation processes of as-cast $\gamma$ grain structures during casting of hyperperitectic carbon steels with 0.15-0.45 mass\% carbon concentrations have been studied by means of a rapid unidirectional solidification technique. In steels with 0.15-0.41 mass\% carbon concentrations, coarse columnar $\gamma$ grains (CCG) with a minor axis diameter of $1-3 \mathrm{~mm}$ developed along the direction of temperature gradient. In a steel with 0.38 mass\% carbon, importantly, columnar $\gamma$ grains (CG) whose minor axis diameter is less than $500 \mu \mathrm{m}$ form before the formation of CCG and the grain structure discontinuously changes from CG to CCG. The fraction of CG region increases with increase in the carbon concentration. In the samples with the carbon concentration higher than 0.43 mass\%, the as-cast structure consists of CG over almost the entire ingots. Analyses on a relation between $\gamma$ grain and dendrite structures and their crystallographic orientations indicate that the formation of CG originates from the primary solidification of $\gamma$ phase instead of $\delta$ phase. This is supported by numerical analysis on the dendrite growths.
\end{abstract}

Keywords: Casting; As-cast austenite grain; Solidification microstructure; EBSD; Phase transition 


\section{Introduction}

Solidification of hyperperitectic carbon steels starts with the primary solidification of $\delta$ dendrite and undergoes the peritectic reaction/transformation $[1,2]$, finally ending up the formation of as-cast $\gamma$ grain structure. The $\gamma$ grains significantly grow after the temperature decreases to a temperature for completion of transformation to $\gamma$ single phase, $T_{\gamma}$. When $T_{\gamma}$ depending on the steel composition becomes lower, the grain growth becomes less significant [3]. In continuous casting processes of peritectic carbon steels with carbon concentrations around the peritectic point, the as-cast $\gamma$ grain structure consists of coarse columnar $\gamma$ grains (CCG) near the slab surfaces. The formation of CCG should be avoided because it causes low ductility and the occurrence of surface cracking in steel slabs. To this end, the detailed understanding of the formation mechanism of the as-cast $\gamma$ grain structure is of great importance.

In earlier works, the as-cast $\gamma$ grain structures in continuous casting processes were analyzed in terms of cooling rate, $T_{\gamma}$ and the mobility of $\gamma$ grain boundary depending on the steel composition [4,5]. It should be noted that the earlier work [4] assumed that the CCG forms by continuous grain growth below $T_{\gamma}$. In Ref. [5], the calculations for $\gamma$ grain size at the surface of slabs and $1 \mathrm{~mm}$ below the surface for the laboratory test samples were conduced based on a model for continuous grain growth below $T_{\gamma}$. In our recent study of hyperperitectic carbon steels of 0.2 and 0.35 mass\% carbon concentrations, however, it was found that the formation of CCG is ascribed to a discontinuous grain growth in which the CCG grow from the mold wall along the temperature gradient at the expense of fine columnar $\gamma$ grains (FCG) existing ahead of the CCG region [6]. The change from FCG to CCG was discontinuous and the boundary between both the regions was clearly identified. The temperature at the growth front of CCG region is always close to $T_{\gamma}$ during the solidification. Hence, the FCG region corresponds to liquid $+\gamma$ two phase field, while the CCG is in $\gamma$ single phase field. The minor axis diameter of FCG is comparable to the primary dendrite arm spacing (DAS) of $\delta$ phase, because the interdendritic liquid phase in FCG region inhibits the growth of FCG along their minor axis direction. The occurrence of the discontinuous growth under various cooling conditions and the formation of CCG by this mechanism were verified by means of phase field simulations in our recent study [7]. It was demonstrated that increase in $T_{\gamma}$ causes a strong tendency for the discontinuous grain growth to occur and the CCG are thereby likely to form.

The 0.2 and 0.35 mass\% carbon steels that we focused in the previous experimental study [6] are prone to exhibit the coarse grain structure because of their high values of $T_{\gamma}$. It is known that in steels with higher carbon concentrations, e.g. 
0.45 mass \% carbon steel, columnar $\gamma$ grains form in the vicinity of the mold wall $[\mathbf{8 , 9}]$. However, to the best of our knowledge, the variations of the morphology and size of as-cast $\gamma$ structures with the carbon concentration have not been scrutinized yet. More importantly, it is still unclear that the discontinuous grain growth mechanism for CCG formation can be applied to the other hyperperitectic carbon steels. In this study, we carry out a systematic investigation on the as-cast $\gamma$ grain structures and their formation mechanisms in carbon steels with different carbon concentrations by the rapid unidirectional solidification technique used in our previous study [6]. It will be demonstrated that the as-cast $\gamma$ grain structure drastically and discontinuously changes with the increase in carbon concentration. In steels with 0.15-0.35 mass \% carbon concentrations, the CCG structure predominantly develops. However, when the carbon concentration is equal to or higher than 0.38 mass \%, the columnar grains (CG), which are distinctly finer than CCG but coarser than FCG, form. Analyses on a relation between $\gamma$ grain and dendrite structures and the crystallographic orientations between $\gamma$ grains and dendrites suggest that the formation of CG in the high carbon steels is attributed to preferential growth of $\gamma$ dendrite instead of $\delta$ dendrite in the primary solidification. The transition of solidification mode from $\delta$ to $\gamma$ solidification is supported by numerical analysis on the dendrite growths. Finally, it was found that regardless of the different mechanism of formation, the size of columnar grains is determined before the cooling process below $T_{\gamma}$, which is in marked contrast to the earlier discussions on the size of columnar grains during continuous casting processes $[4,5]$.

\section{Experimental}

In the present study, we focused on hyperperitectic carbon steels with the carbon concentration ranging between 0.15 and 0.45 mass $\%$. A forged 0.2 mass\% carbon steel bar was cut and melted with electrolytic pure iron, an Fe-Mn alloy and pure Si to fabricate 0.15 mass\% carbon samples. A forged 0.45 mass\% carbon steel bar was cut and melted with the 0.2 mass\% carbon steel bar to fabricate the samples with the carbon concentration from 0.2 to 0.45 mass $\%$. The chemical compositions of the steels are shown in Table 1. For the sake of convenience, the sample name given in Table 1 is used hereafter such as $0.15 \mathrm{C}$ sample for 0.15 mass\% carbon steel. The carbon concentration is denoted by $x_{\mathrm{c}}$. It was preliminary confirmed from the thermodynamic calculation with a thermodynamic database, PanIron [10], that all the steels described above are of hyperperitectic in the equilibrium condition. In addition to the hyperperitectic steels, we made 0.7 mass\% carbon steel ( $0.7 \mathrm{C}$ sample) of which 
the primary crystal is $\gamma$ phase and the solidification finishes without the peritectic reaction and transformation according to the thermodynamic calculation. The reason for casting of $0.7 \mathrm{C}$ sample will be clarified later.

The sample of $180 \mathrm{~g}$ was put in a cylindrical $\mathrm{MgO}$ crucible with an inner diameter of 28 $\mathrm{mm}$ and a depth of $70 \mathrm{~mm}$ and melted at $1570{ }^{\circ} \mathrm{C}$ in a SiC furnace filled with Ar gas of five-nine purity and held for an hour. Then, the melted sample was cast into rapid unidirectional solidification equipment. This equipment consists of a water cooled copper mold and a $\mathrm{MgO}$ pipe put on the copper mold. The MgO pipe was preheated at $1570^{\circ} \mathrm{C}$ and it plays a role of a sidewall of the cast. The cast steel solidifies unidirectionally from the bottom (copper mold side) toward the top. The ingot cooled to room temperature has a columnar shape with a height of $40 \mathrm{~mm}$ and a diameter of $28 \mathrm{~mm}$. In this experimental procedures, the liquid steel directly touches with the chill copper mold, therefore, it is expected that the initial heat flux should reach about $10 \mathrm{MW} / \mathrm{m}^{2}$ [11], which is higher than a few $\mathrm{MW} / \mathrm{m}^{2}$ in ordinary C.C. processes [12]. However, such a high initial heat flux immediately decreases in a second to the level of ordinary C.C. processes [11] and hence, the cooling rates in this equipment should not be substantially different from that of ordinary C.C. processes. In fact, the measured cooling rates at $10 \mathrm{~mm}$ and $15 \mathrm{~mm}$ heights from the mold in this equipment are quite similar to that of the practical C.C. process [6]. Moreover, the average $\gamma$ grain size in $0.2 \mathrm{C}$ steel which was cast into this equipment [6] were found comparable to the average $\gamma$ grain size in practical C.C. slab with a similar carbon concentration [13]. It is considered accordingly that the as-cast microstructure and its formation process observed in this study should be similar to those in practical C.C. steels.

As described in detail in the previous report [6], this equipment enables a rapid drop of the cast into intensely agitated iced water together with the $\mathrm{MgO}$ pipe and hence it enables the analysis on frozen structure of solidifying samples. When the cast was quenched during the solidification, the MgO pipe was crashed by agitating steel chains in the quenching equipment and the liquid phase remaining in the solidifying sample was flied off, leaving only the solidified part of the sample. Therefore, the height of the ingot was shorter than $40 \mathrm{~mm}$ when quenched during the solidification. The details of the equipment are found in Ref. [6].

The cast ingot was sectioned vertically along the center axis of the ingot. The section was polished and etched with 3\%-nital and Oberhöffer's solutions to observe the as-cast $\gamma$ grain and dendrite structures, respectively. Also, we carried out metallographic observations on the horizontal section at several heights from the bottom of the mold. The microstructural observation was performed on the region from the bottom to a 
height of $20 \mathrm{~mm}$ from the copper mold, because the cooling process at the top part of the sample should be affected by air cooling condition, which is not our concern. In order to investigate the crystallographic orientation of the as-cast $\gamma$ grains, an electron backscattering diffraction (EBSD) analysis was performed on the horizontal sections.

\section{Results and discussion}

\subsection{Variation of as-cast y grain structure}

Figures 1(a)-(d) show the as-cast $\gamma$ grain structures in 0.15C, 0.25C, 0.4C and $0.45 \mathrm{C}$ samples cooled to room temperature on the copper mold. In $0.15 \mathrm{C}$ sample, the as-cast structure consists of coarse columnar $\gamma$ grains (CCG) over the entire region. The average minor axis diameter, $d_{\mathrm{m}}$, of CCG is $1-3 \mathrm{~mm}$. In $0.25 \mathrm{C}$ sample, equiaxed $\gamma$ grains (EG) form in the vicinity of the copper mold and it gradually changes into CCG with increase in the distance from the copper mold. However, in 0.4C sample, distinct columnar grains appear in the vicinity of the mold. After the formation of the EG near the copper mold, the columnar $\gamma$ grains of which $d_{\mathrm{m}}$ is less than $500 \mu \mathrm{m}$ form and then the grain structure suddenly changes to CCG. In 0.45C sample, the columnar grains with $d_{\mathrm{m}}<500 \mu \mathrm{m}$ develop over almost the whole region in the sample.

Figure 2(a) shows the relationship between the average minor axis diameter, $d_{\mathrm{m}}$, and the distance from copper mold. $d_{\mathrm{m}}$ corresponds to the area-equivalent circle diameter measured on the horizontal sections at different heights from the copper mold. More than 100 of $\gamma$ grains were counted in a selected area on each section. As previously reported [13], $d_{\mathrm{m}}$ increases with increase in the distance from the copper mold in $0.15 \mathrm{C}$ and $0.2 \mathrm{C}$ samples and decreases with increase in the carbon concentration. However, it is important to note that $d_{\mathrm{m}}$ in $0.4 \mathrm{C}$ sample drastically increases when the structure changes from columnar grains with $d_{\mathrm{m}}<500 \mu \mathrm{m}$ to CCG at a position indicated by the vertical dotted line. In $0.45 \mathrm{C}$ sample, $d_{\mathrm{m}}$ is always less than $500 \mu \mathrm{m}$. The measured values of $d_{\mathrm{m}}$ in $0.2 \mathrm{C}$ and $0.45 \mathrm{C}$ samples are comparable to $d_{\mathrm{m}}$ observed in ordinary C.C. slab with the similar carbon concentrations [13]. In the following discussions, we define the grain region where the average aspect ratio is smaller than 2 as EG region and the region with the average aspect ratio larger than 2 as columnar grain region. The columnar grain region is further classified into three types based on the value of $d_{\mathrm{m}}$; the first is the CCG region where $d_{\mathrm{m}}$ is about $1-3 \mathrm{~mm}$, the second is the columnar $\gamma$ grain (CG) region where $d_{\mathrm{m}}$ is $200-500 \mu \mathrm{m}$ and the third is the FCG region where $d_{\mathrm{m}}$ is less than $200 \mu \mathrm{m}$.

Figure 2(b) shows variation of the length of the EG and CG regions in all the samples. As can be seen in Fig. 2(b), the length of EG region increases with increasing 
$x_{\mathrm{c}}$ to 0.35 mass\%. When $x_{\mathrm{c}}$ is higher than 0.35 mass\%, the EG region almost disappears. Instead, the CG region forms near the mold side. The length of CG region increases with increase in $x_{\mathrm{c}}$ and, suddenly increases up to about $20 \mathrm{~mm}$ when $x_{\mathrm{c}} \geq 0.43$. Almost the whole structure consists of CG in 0.43C and 0.45C samples. Figure 2(c) shows the schematic illustrations of the variation of as-cast $\gamma$ structures. The microstructure varies from CCG+EG to CG+EG structure with increase in $x_{\mathrm{c}}$.

As shown in Figs. 1 and 2, there are three types of grain regions, EG, CCG and CG regions. In our previous study [6], it was revealed that the formation of the CCG structure in $0.2 \mathrm{C}$ and $0.35 \mathrm{C}$ samples is ascribed to discontinuous grain growth in which the CCG grows along the temperature gradient at the expense of FCG existing ahead of CCG region. The temperature of FCG region corresponds to liquid $+\gamma$ two phase field and $d_{\mathrm{m}}$ of FCG is comparable to the primary DAS of $\delta$ dendrite $(100-200 \mu \mathrm{m})$. Our numerical analysis showed that the discontinuous grain growth, thus formation of CCG occurs when the migration velocity of the FCG/CCG region boundary, $V_{\gamma}$, is higher than the moving velocity of $T_{\gamma}$ position, $V_{T}$ [7]. On the other hand, when $V_{\gamma}<V_{T}$, the continuous grain growth arises and EG structure accordingly forms. Since $V_{\gamma}$ decreases with decrease in $T_{\gamma}$ and thereby it decreases with increase in $x_{\mathrm{c}}$, the EG structure tends to form in steels with low $T_{\gamma}$ (viz., high $x_{\mathrm{c}}$ ) under a given cooling condition. This explains the increase of EG region with increase in $x_{\mathrm{c}}$ from 0.15 to 0.35 mass\% shown in Fig. 2(b). However, the appearance of CG region in samples with $x_{\mathrm{c}} \geq 0.38$ cannot be explained by the occurrence of discontinuous or continuous grain growth.

\subsection{Relationship between the as-cast y grain structure and dendrite structure}

Solidification of hyperperitectic carbon steels generally experiences the primary solidification of $\delta$ phase and the peritectic reaction/transformation followed by the formation of as-cast $\gamma$ grain structure. In this section, we investigate a relationship between the as-cast $\gamma$ structure and dendrite structure.

Figures 3(a) and (b) show the comparison between the as-cast $\gamma$ structure and the dendrite structure in the CCG and CG regions, respectively. The bottom side of each micrograph corresponds to the copper mold side and the vertical direction is the direction of unidirectional solidification. The dendrite structure consists of dendrite assemblages in which all columnar dendrites grow in the same direction. In Fig. 3(a), the $\gamma$ grain boundaries exist independently of the array of dendrite assemblies. Namely, no correlation is observed between the dendrite and $\gamma$ grain structures. This is also the case in CCG region observed in 0.4C sample as can be seen in Fig. 3(b) where for comparison, the grain boundaries of CCG1, CCG2 and CCG3 in Fig. 3(b)-(i) are drawn 
in the dendrite structure in Fig. 3(b)-(ii). Furthermore, although not shown here, no correlation is observed in EG region. However, a definite relationship appears between $\gamma$ grain and dendrite structure in CG region. The lower part of Fig. 3(b)-(i) corresponds to the CG. As an example, the grain boundary of "CG1" in Fig. 3(b)-(i) was drawn in dendrite structure in Fig. 3(b)-(ii). One can see that the position of grain boundary of CG1 coincides with the position of the boundary of dendrite assemblage. This relationship always exists between CG and dendrite structures in CG region of the other samples. Moreover, it should be pointed out that the dendrite assemblages change their growth directions near CG/CCG region boundary, as is illustrated in Fig. 3(b)-(iii) where the $\gamma$ grain boundaries and the boundary for the change of growth directions of dendrite assemblies are indicated by the solid and dashed lines, respectively.

As shown in Fig. 3, the position of $\gamma$ grain boundaries coincides with the position of boundaries between dendrite assemblages in CG region. In order to investigate the relationship more quantitatively, we counted the number of dendrite assemblages per $\gamma$ grain on horizontal sections. Figure 4 shows the number of dendrite assemblages per $\gamma$ grain with respect to the distance from the copper mold. The average number of the dendrite assemblages per $\gamma$ grain is in the range of 4-7 in the CCG and EG region of $0.2 \mathrm{C}$ and $0.25 \mathrm{C}$ samples. This is also the case for CCG region of $0.4 \mathrm{C}$ sample. However, the number of the dendrite assemblage is almost 1 in CG region of $0.4 \mathrm{C}$ and $0.45 \mathrm{C}$ samples. In other words, there is always one-to-one correspondence between the $\gamma$ grain and dendrite assemblage in $\mathrm{CG}$ region.

As already described, in $0.2 \mathrm{C}$ and $0.35 \mathrm{C}$ samples, the FCG form from the primary $\delta$-dendrites and the CCG develop by the discontinuous grain growth [6]. When $T_{\gamma}$ is low, the continuous grain growth from FCG occurs and it results in the formation of EG structure [7]. It is important to notice that when the FCG form, the relationship between dendrites and grown $\gamma$ grains does not necessarily exist irrespective of the discontinuous or continuous grain growth. In fact, there is no correlation found between $\gamma$ grain and dendrite structures in EG and CCG regions in Figs. 3 and 4. Hence, the existence of one-to-one correspondence in CG region indicates that the CG should originate from a different mechanism of formation. This point is further discussed in the following sections.

\section{3. $y$ grain structure during the solidification}

In this section, we focus on the structure in solidifying sample. Figure 5(a) shows the microstructure of $0.2 \mathrm{C}$ sample quenched at $30 \mathrm{~s}$ after casting. The CCG develop from the bottom to upper side. At the upper part of micrograph, the FCG exist. 
The FCG/CCG region boundary is clearly identified. Although not demonstrated clearly, the size of FCG is comparable to the primary DAS and several FCG exist inside a dendrite assemblage in FCG region, which indicates that $\gamma$ phases with different crystallographic orientations nucleate from $\delta$ dendrites.

Figure 5(b)-(d) show the as-cast $\gamma$ structure in $0.35 \mathrm{C}, 0.4 \mathrm{C}$ and $0.45 \mathrm{C}$ samples quenched at 30s after casting. The FCG exist ahead of CCG in 0.35C sample. In 0.4C sample, the grain structures change from CG to CCG and then FCG exist ahead of CCG. Length of the FCG region increases with increase in $x_{c}$ from 0.2 (Fig. 5(a)) to 0.4 (Fig. $5(c)$ ) which is natural consequence of increase of the range of $L+\gamma$ temperature region. Contrary to our expectation, however, the FCG structure does not exist in $0.45 \mathrm{C}$ sample (Fig. 5(d)) and the structure fully consists of CG. This fact also suggests that the formation mechanism of CG is different from the discontinuous and continuous growth mechanisms.

\subsection{Crystallographic relationship between dendrite and as-cast y grain}

As observed in Fig. 5(c), the structure in solidifying 0.4C sample quenched at 30s after casting exhibits EG, CG, CCG and FCG regions from the copper mold to upper part of the ingot. First, we focus on the crystallographic orientation in CG region. The $\gamma$ grain structure in the quenched sample discussed above is the martensite structure. The martensite laths have an orientation relationship (OR) with the prior $\gamma$ phase, i.e., K-S relationship, (111) $)_{\gamma} / /(011)_{\mathrm{M}}$ and $[\overline{1} 01]_{\gamma} / /[\overline{1} \overline{1} 1]_{\mathrm{M}}[\mathbf{1 4}]$. Therefore, it is possible to identify the crystallographic orientation of $\gamma$ grain based on EBSD analysis of the martensite structure $[\mathbf{1 5}, \mathbf{1 6}]$.

Figure 6(a) shows the dendrite structure in CG region of 0.4C sample on the horizontal section. The arrows indicate the growth directions of the secondary dendrite arm. This observation area was selected from microstructural observations of vertical section so that the growth direction of the primary dendrite arms of focus is almost completely perpendicular to the copper mold. The rectangular region specified by solid line in Fig. 6(a) corresponds to the area analyzed by EBSD. Figures 6(b) and (c) show the inverse pole figure (IPF) and the pole figure (PF) of $\{001\}_{M}$ in the analyzed area. According to the K-S relationship [14], 24 different variants of martensite are possible to form in a $\gamma$ grain. Pole figure of the possible 24 variants is fitted into $\{001\}_{M}$ data measured by the EBSD, from which the crystallographic orientation of the prior $\gamma$ phase was determined. The result of orientation of the prior $\gamma$ phase is indicated by red plots in Fig. 6(c). The important finding in Fig. 6(c) is that $<100>$ directions of $\gamma$ phase exactly coincide with the growth directions of the primary and secondary dendrite arms. The 
growth direction of dendrite arms in bcc and fcc crystals corresponds to their $<100>$ directions [17]. Hence, $<100>$ direction of CG is in agreement with $<100>$ direction of dendrite. We analyzed several different area of CG region and confirmed that this relation is always true in CG region.

Next, the same analysis was conducted for FCG region in $0.4 \mathrm{C}$ sample. The results are shown in Fig. 7. It is seen that $\langle 100>$ of $\gamma$ phase is not equivalent to the direction of dendrite arms. This result should be naturally expected as long as the $\gamma$ phase nucleates from the dendrite and it grows to FCG. Namely, the dendrites observed in FCG region of $0.4 \mathrm{C}$ sample correspond to the $\delta$ dendrites.

\subsection{Casting of sample with the primary $\gamma$ solidification}

Our investigations showed that i) the size of CG is distinctly different from that of CCG and it is comparable to the size of dendrite assemblage, ii) the FCG does not exist ahead of CG region during the solidification process and iii) $<100>$ direction of CG corresponds to $<100>$ direction of dendrite in CG region. These facts suggest a possibility that in CG region the primary solidification of $\gamma$ instead of $\delta$ phase occurs and the solidification finishes without the peritectic reaction and transformation. When the $\gamma$ phase solidifies as the primary crystal, the columnar dendrite arm grows in $<100>$ direction of $\gamma$ phase. The columnar dendrites in a dendrite assemblage have the same crystallographic orientation and therefore they form a columnar $\gamma$ grain after the solidification completes. This is consistent with the existence of one-to-one correspondence between $\gamma$ grain and dendrite assemblage shown in Figs. 3 and 4. FCG formed after $\delta$ to $\gamma$ transformation should not exist in this case. Also, since the grain size of CG should depend on the size of dendrite assemblages in this case, the distinct grain size difference between CCG and CG should appear as seen in Fig. 2(a).

In order to check the possibility of primary solidification of $\gamma$, we performed casting experiment of $0.7 \mathrm{C}$ sample. It is noted that the primary crystal in $0.7 \mathrm{C}$ sample is $\gamma$ phase according to the thermodynamic calculation. Figure 8 shows the $\gamma$ structure in 0.7C sample quenched at 30s after casting which consists of columnar grains with $d_{m}<$ $500 \mu \mathrm{m}$ over almost the whole ingot. This grain structure is almost identical with the CG observed in the steels with $x_{c} \geq 0.38$. Actually, $d_{\mathrm{m}}$ of $0.7 \mathrm{C}$ sample at various distances from the bottom coincides well with those of $0.45 \mathrm{C}$ sample. Furthermore, we confirmed that there is one-to-one correspondence between the $\gamma$ grain and dendrite assemblage in 0.7C sample. Hence, this result strongly suggests that the CG region in hyperperitectic steels with $x_{c} \geq 0.38$ originates from the primary solidification of $\gamma$ phase.

As shown in Fig. 2, in 0.38C, 0.4C and 0.41C samples, the as-cast $\gamma$ grain 
structure changed from CG to CCG. This transition from CG to CCG should originate from the transition of the primary crystal from $\gamma$ to $\delta$ phase. The change of growth directions of dendrite assemblages discussed in Fig. 3(c) seems to support the possibility of this transition. Then, the results shown in Figs. 1, 2 and 4 suggest that the primary solidification of $\gamma$ phase should be likely to occur when the cooling rate is high and/or $x_{\mathrm{c}}$ is high. In order to check this point, we performed a numerical analysis on the dendrite growths of $\delta$ and $\gamma$ phases.

\subsection{Numerical analysis for the transition of primary crystal}

We analyze the dendrite growth velocities of $\delta$ and $\gamma$ phases based on the Kurz, Giovanola, and Trivedi (KGT) model [18]. The approach developed by Rappaz [19] for multi-component system is utilized. Within the KGT model, the dendrite tip radius, $r$, is given by the solution of the following equation.

$$
G r^{2}+2 r \sum_{i}^{N} \frac{\left\{m_{i} P e_{i}\left(1-k_{i}\right) x_{0, i}\left(1-k_{i}\right) \xi_{c i}\left(P e_{i}\right)\right\}}{\left\{1-\left(1-k_{i}\right) I_{v}\left(P e_{i}\right)\right\}}+4 \pi^{2} \Gamma=0
$$

where $G$ is the temperature gradient, $m_{i}$ is the slope of liquidus for constituent $i, N$ is the number of the constituents in the alloy system, $x_{0, i}$ is the initial concentration of the

constituent $i, k_{i}$ is the partition coefficient for constituent $i, \Gamma$ is the Gibbs-Thomson coefficient. $P e_{i}$ is the Peclet number for constituent $i$, given by $P e_{i}=r V /\left(2 D_{i}\right)$ with the migration velocity of dendrite tip, $V$, and diffusion coefficient of constituent $i$, in the liquid phase, $D_{i} . I_{v}\left(P e_{i}\right)$ is the Ivantsov function and $\xi_{c}\left(P e_{i}\right)$ is the stability parameter given as follows,

$$
\xi_{c}\left(P e_{i}\right)=1-\frac{2 k_{i}}{\left[1+\left(2 \pi / P e_{i}\right)^{2}\right]^{1 / 2}-1+2 k_{i}}
$$

The dendrite tip temperature, $T^{*}$, is expressed by the following equation,

$$
T^{*}=T_{M}-\sum_{i=1}^{N} m_{i} x_{i}^{*}-\frac{2 \Gamma}{r}
$$

where $T_{M}$ is the melting point of Fe, $x_{i}^{*}$ is the concentration of the constituent $i$ in the liquid phase at the liquid/solid interface. The temperature dependence of $D_{i}$ and solidification velocity dependence of $k_{i}[20]$ were also taken into account.

Eqs.(1) and (3) were numerically solved for $\gamma$ and $\delta$ dendrite growths using the physical parameters listed in Table 2. Since the temperature gradient, $G$, did not 
significantly affect the calculation results, $G$ was fixed at $10^{4} \mathrm{~K} / \mathrm{m}$, which was approximated from the results of temperature measurements in our experiments [6]. $m_{i}$ and $k_{i}$ were calculated by the CALPHAD method [22] using the database of PanIron [10].

Figure 9(a) shows the calculated relationships between the dendrite tip velocity and the tip temperature for $\delta$ and $\gamma$ dendrite growths in Fe-0.4C-0.8Mn-0.2Si-0.02P (mass\%) system. The tip temperature of both phases decreases with increase in the tip velocity. As is commonly discussed in construction of microstructure selection map, we regard the phase growing at higher tip temperature as the primary crystal. Hence, the primary crystal changes from $\delta$ to $\gamma$ phase when the velocity is higher than the value indicated by the vertical dotted line which is called the transition velocity. The effect of $x_{c}$ on the transition velocity was summarized in Fig. 9(b). This result indicates that when the solidification velocity is lower (higher) than the solid line, the primary crystal corresponds to $\delta(\gamma)$ phase. In Fig. 9(b), the result for Fe-C binary system is also indicated by the dotted line. It is noted that the increase in $x_{\mathrm{c}}$ and the addition of the other alloying elements lead to the decrease of the transition velocity. Now, we compare the calculated transition velocity with the solidification velocity in the present experiments. The solidification velocity in the present experiments was roughly estimated as follows. In our experiment, the liquid phase in the solidifying sample was flied off due to the strong agitation by steel chains during the quenching operation and only the solidified part was left. Therefore, the solidification velocity can be very roughly estimated from the height of the samples quenched at different times. From this measurement, the minimum solidification velocity was estimated to be about $0.5 \mathrm{~mm} \cdot \mathrm{s}^{-1}$. As for the maximum solidification velocity near the copper mold, we refer to about $3 \mathrm{~mm} \cdot \mathrm{s}^{-1}$, which was estimated in continuously cast slab by the analysis of heat flow [12], because the cooling condition and the as-cast structures in our experimental equipment are quite similar to those in the continuous casting [13]. In our experiment, the initial heat flux should be higher than that in ordinary C.C. process since the liquid steel directly touches with the chill copper mold. However, as mentioned in the previous section, the initial high heat flux immediately decreases to the level of the ordinary C.C. process [11]. Therefore, it should be allowed to refer to the maximum solidification rate of $3 \mathrm{~mm} \cdot \mathrm{s}^{-1}$. These minimum and maximum velocities are specified in Fig. 9(b). From this result, one can realize that the primary crystal is always $\delta$ phase when $x_{\mathrm{c}}<0.37$. In steels with $0.37<x_{\mathrm{C}}<0.42$, however, the primary solidification of $\gamma$ phase occurs near the mold side and the primary crystal changes from $\gamma$ to $\delta$ phase during the solidification. When $x_{\mathrm{C}}>0.42$, the primary crystal is always $\gamma$ phase in the present equipment. This 
result is quite consistent with the variation of as-cast $\gamma$ grain structure, viz., the formation of CG region as shown in Figs. 1-4. Although the estimation of solidification velocity is quite rough, these results strongly suggest that the formation of CG region should originate from the primary solidification of $\gamma$ phase. The similarities in the cooling rates and the measured $\gamma$ grain sizes between our experiment and C.C. processes indicates that the formation of CG should occur in practical C.C. processes.

It should be noted that our analysis does not claim that the preferential nucleation of $\gamma$ phase takes place in CG region. In the steels with $x_{\mathrm{c}} \geq 0.38, \delta$ phase might nucleate near the copper mold as the primary crystal at very beginning of the solidification. Even so, the subsequently formed $\gamma$ phase should get ahead of $\delta$ dendrite. Then, the solidification front corresponds to the $\gamma$ dendrite, from which region the solidification does not undergo the peritectic reaction and transformation and results in the formation of CG. This is what our analysis suggests.

In our previous study on the CCG formation [6], it was found that the minor axis diameter of CCG increases only near the FCG/CCG region boundary and it does not increase below $T_{\gamma}$ during the CCG formation in $0.2 \mathrm{C}$ and $0.35 \mathrm{C}$ samples. In the present study, one-to-one correspondence between CG and dendrite assemblages was observed. Hence, CG does not virtually grow during the cooling after the completion of solidification. Then, it is important to point out that regardless of the different mechanism of formation, the size of columnar grains (CCG or CG) is determined before the cooling process below $T_{\gamma}$, which is in marked contrast to the earlier discussion on the size of columnar grains during continuous casting processes [4]. The size of CCG is associated with the discontinuous grain growth near $T_{\gamma}$, while the size of CG is related to the dendrite growth of $\gamma$ phase. Hence, different methods for grain refinement of as-cast $\gamma$ structure should be applied to CCG and CG regions. For instance, the prevention of formation of CCG might be realized, e.g., by utilizing pinning effect which inhibits the discontinuous grain growth. As for CG region, the grain refinement of as-cast $\gamma$ structure corresponds to the refinement of $\gamma$ dendrite structure. This point remains to be addressed in a future work.

\section{Conclusions}

In the present study, the as-cast $\gamma$ grain structures and their formation mechanisms in hyperperitectic carbon steels were investigated by means of rapid unidirectional solidification technique. The important findings are summarized as follows, 
1) In steels with the carbon concentration $x_{c}$ less than 0.38 , the as-cast structures consist of equiaxed grains (EG) and coarse columnar $\gamma$ grains (CCG) whose average minor axis diameter $d_{\mathrm{m}}$ is $1-3 \mathrm{~mm}$. When $x_{\mathrm{c}} \geq 0.38$, columnar $\gamma$ grains (CG) whose average minor axis diameter $d_{\mathrm{m}}$ is $200-500 \mu \mathrm{m}$ appear near the copper mold and the grain structure abruptly changes from CG to CCG. The length of CG gradually increases with increasing $x_{\mathrm{c}}$ to $x_{\mathrm{C}}=0.42$. Almost the whole structure consists of the CG in steels with $x_{\mathrm{c}} \geq 0.43$.

2) The positions of $\gamma$ grain boundary coincide with the positions of boundaries of dendrite assemblages in CG region. In other words, the size and shape of $\gamma$ grain accord with those of dendrite assemblage in CG region. However, there is no such a correlation between the $\gamma$ grain and the dendrite structures in EG and CCG regions.

3) In the solidifying samples, fine columnar $\gamma$ grains (FCG) with $d_{\mathrm{m}}$ less than $200 \mu \mathrm{m}$ exist in front of the growing CCG, while the FCG does not exist in front of the CG region.

4) In CG region, there is a crystallographic orientation relationship, $\{100\}_{\gamma} / /\{100\}_{d}$ and $<100>_{\gamma} / /<100>_{\mathrm{d}}$ where the subscripts $\gamma$ and $d$ represent $\gamma$ phase and dendrite, respectively. However, FCG does not exhibit such a relationship.

5) The above-mentioned findings indicate that the formation of CG originates from the occurrence of primary solidification of $\gamma$ phase. This is well supported by our numerical analyses of $\delta$ and $\gamma$ dendrite growths based on the KGT model. 


\section{References}

[1] Fredriksson H. Met Sci 1976;10:77.

[2] Kerr HW and Kurz W. Int Mater Rev 1996;41:129.

[3] Maehara Y, Yasumoto K, Sugitani Y and Gunji K. ISIJ Int 1985;25:1045.

[4] Yoshida N, Kobayashi Y and Nagai K. Tetsu-to-Hagané 2004;90:198.

[5] Bernhard C, Reiter J and Presslinger H. Metall Mater Trans B 2008;39B:885.

[6] Tsuchiya S, Ohno M, Matsuura K and Isobe K. Acta Mater 2011;59:3334.

[7] Ohno M, Tsuchiya S and Matsuura K. Acta Mater 2011;59: 5700.

[8] Ohno M and Matsuura K. ISIJ Int 2008;48:1373.

[9] Mizuno H, Esaka H, Shinozuka K and Tamura M. ISIJ Int 2008;48:270.

[10] CompuTherm LLC: http://www.computherm.com/. Last accessed date: 09/13/2011.

[11] Todoroki H and Phinichka N. ISIJ Int 2009;49:1347.

[12] Hanao M, Kawamoto M and Yamanaka A. ISIJ Int 2009;49:365.

[13] Reiter J, Bernhard C and Presslinger H. Mater Charact 2008;59:737.

[14] Kurdjumov G and Sachs GZ. Phys 1930;64:325.

[15] Morito S, Tanaka H, Konishi R, Furuhara T and Maki T. Acta Mater 2003;51:1789.

[16] Miyamoto G, Iwata N, Takayama N and Furuhara T. Acta Mater 2010;58:6393.

[17] Kurz W and Fisher DJ. Fundamentals of Solidification. Trans Tech

Publications, Aedermannsdorf. Switzerland; 1992: 63.

[18] Kurz W, Giovanola B and Trivedi R. Acta Metall 1986;34:823.

[19] Rappaz M, David SA, Vitek JM and Boatner LA. Metall Trans A 1990;21A:1767.

[20] Aziz MJ. J Appl Phys 1982;53:1158.

[21] Matsumiya T, Kajioka H, Mizoguchi S, Ueshima Y and Esaka H. ISIJ Int 1984;24:873.

[22] Kaufman L and Bernstein L. Computer Calculation of Phase Diagrams with

Special Reference to Refractory Materials. Academic Press. New York;1970:1. 
Table 1. Chemical compositions of the samples employed in this study.

\begin{tabular}{|c|c|c|c|c|c|c|c|c|}
\hline \multirow{2}{*}{$\begin{array}{c}\text { Sample } \\
\text { name }\end{array}$} & \multicolumn{8}{|c|}{ Steel composition, in mass \% } \\
\hline & C & Si & Mn & $\mathbf{P}$ & $\mathbf{S}$ & Al & $\mathbf{O}$ & $\mathbf{N}$ \\
\hline $\mathbf{0 . 1 5 C}$ & 0.15 & 0.20 & 0.80 & 0.02 & 0.002 & 0.04 & 0.002 & 0.0038 \\
\hline $0.2 \mathrm{C}$ & 0.20 & 0.21 & 0.79 & 0.02 & 0.003 & 0.04 & 0.002 & 0.0051 \\
\hline $0.25 \mathrm{C}$ & 0.25 & 0.21 & 0.78 & 0.02 & 0.007 & 0.04 & 0.002 & 0.0055 \\
\hline $0.35 \mathrm{C}$ & 0.35 & 0.21 & 0.74 & 0.02 & 0.01 & 0.03 & 0.002 & 0.0053 \\
\hline $0.38 \mathrm{C}$ & 0.38 & 0.21 & 0.73 & 0.02 & 0.012 & 0.03 & 0.002 & 0.0051 \\
\hline $0.4 \mathrm{C}$ & 0.40 & 0.21 & 0.72 & 0.02 & 0.012 & 0.03 & 0.002 & 0.0051 \\
\hline $0.41 C$ & 0.41 & 0.21 & 0.71 & 0.02 & 0.013 & 0.03 & 0.002 & 0.0051 \\
\hline $0.43 C$ & 0.43 & 0.21 & 0.71 & 0.02 & 0.014 & 0.03 & 0.002 & 0.0051 \\
\hline $0.45 C$ & 0.45 & 0.21 & 0.70 & 0.02 & 0.015 & 0.03 & 0.002 & 0.0051 \\
\hline $0.7 C^{*}$ & 0.70 & 0.20 & 0.79 & 0.02 & 0.014 & 0.02 & 0.002 & 0.0046 \\
\hline
\end{tabular}

*Prepared as a sample which solidifies without peritectic reaction/ transformation. (Discussed in section 3.5) 
Table 2. Physical parameters employed in calculations for the dendrite growth.

\begin{tabular}{|c|c|c|c|}
\hline Physical parameters & $\delta$ & $\gamma$ & Liquid \\
\hline$\Gamma$ : Gibbs-Thomson coefficient (mK) & $2.6 \times 10^{-7}$ & $3.2 \times 10^{-7}$ & \\
\hline$D_{0, \mathrm{C}}$ : Proportionality diffusion coefficient for C $\left(\mathrm{m}^{2} / \mathrm{s}\right)$ & & & $5.2 \times 10^{-7}$ \\
\hline$Q_{\mathrm{C}}:$ Activation energy for diffusion of $\mathrm{C}(\mathrm{J} / \mathrm{mol})$ & & & 49023 \\
\hline$D_{0, \mathrm{Mn}}$ : Proportionality diffusion coefficient for $\mathrm{Mn}\left(\mathrm{m}^{2} / \mathrm{s}\right)$ & & & $3.85 \times 10^{-7}$ \\
\hline$Q_{\mathrm{Mn}}:$ Activation energy for diffusion of $\mathrm{Mn}(\mathrm{J} / \mathrm{mol})$ & & & 69554 \\
\hline$D_{0, \mathrm{Si}}:$ Proportionality diffusion coefficient for $\mathrm{Si}\left(\mathrm{m}^{2} / \mathrm{s}\right)$ & & & $5.14 \times 10^{-8}$ \\
\hline$Q_{\mathrm{Si}}:$ Activation energy for diffusion of $\mathrm{Si}(\mathrm{J} / \mathrm{mol})$ & & & 38338 \\
\hline$D_{0, \mathrm{P}}:$ Proportionality diffusion coefficient for $\mathrm{P}\left(\mathrm{m}^{2} / \mathrm{s}\right)$ & & & $1.35 \times 10^{-5}$ \\
\hline$Q_{\mathrm{p}}:$ Activation energy for diffusion of $\mathrm{P}(\mathrm{J} / \mathrm{mol})$ & & & 99303 \\
\hline$G:$ Temperature gradient $(\mathrm{K} / \mathrm{m})$ & & & 10000 \\
\hline$k_{\mathrm{C}}:$ Partition coefficient of $\mathrm{C}$ & 0.16 & 0.33 & \\
\hline$k_{\mathrm{Mn}}:$ Partition coefficient of Mn & 0.7 & 0.72 & \\
\hline$k_{\mathrm{Si}}:$ Partition coefficient of $\mathrm{Si}$ & 0.68 & 0.65 & \\
\hline$k_{\mathrm{P}}:$ Partition coefficient of $\mathrm{P}$ & 0.29 & 0.2 & \\
\hline$m_{\mathrm{C}}:$ Liquidus slope for $\mathrm{C}(\mathrm{K} / \mathrm{mass} \%)$ & -86 & -64 & \\
\hline$m_{\mathrm{Mn}}:$ Liquidus slope for $\mathrm{Mn}(\mathrm{K} / \mathrm{mass} \%)$ & -5.3 & -4.2 & \\
\hline$m_{\mathrm{Si}}:$ Liquidus slope for Si (K/mass\%) & -12.4 & -11.8 & \\
\hline$m_{\mathrm{P}}:$ Liquidus slope for $\mathrm{P}(\mathrm{K} / \mathrm{mass} \%)$ & -29.3 & -29.3 & \\
\hline$T_{\mathrm{M}}:$ Melting point of pure metal (K) & 1811 & 1800 & \\
\hline
\end{tabular}


(a)

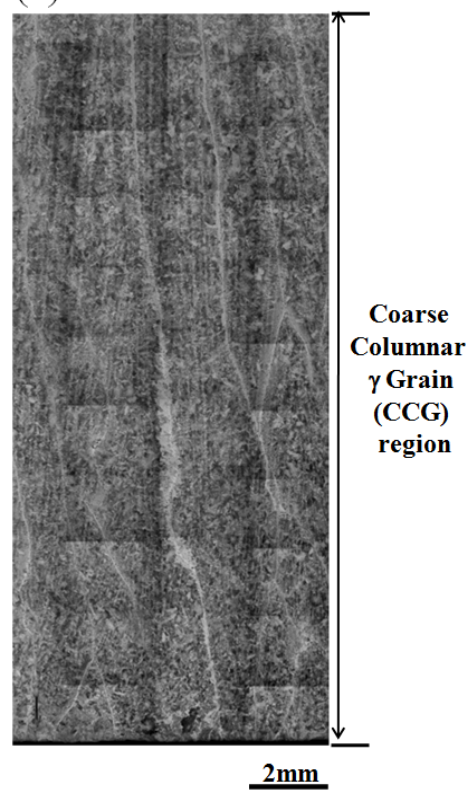

(c)

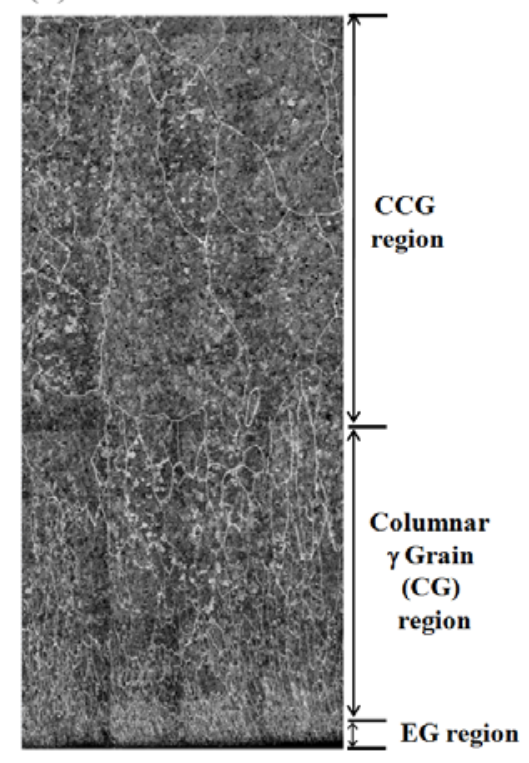

(b)

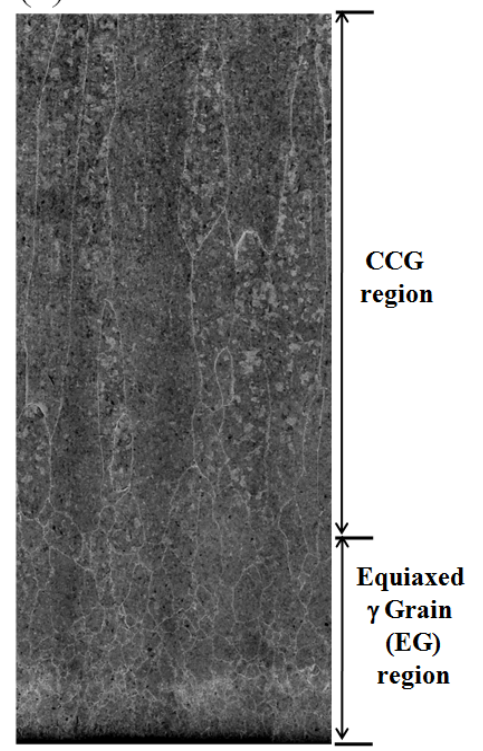

(d)

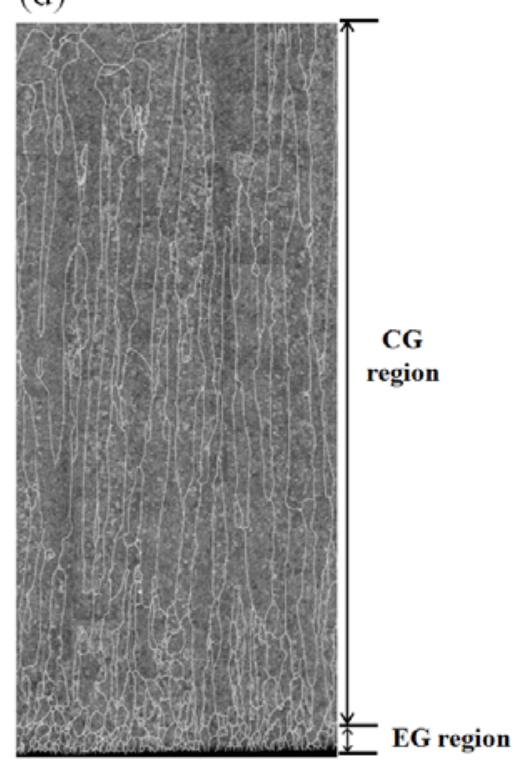

Fig. 1. Microstructures of $0.15 \mathrm{C}, 0.25 \mathrm{C}, 0.4 \mathrm{C}$ and $0.45 \mathrm{C}$ samples naturally cooled to room temperature. The bottom and the top parts of micrographs correspond to the copper mold side and the upper side of the ingot, respectively. The solidification unidirectionally proceeded from the bottom to top side. The bright boundaries in Figs. 1 (a)-(d) show the as-cast $\gamma$ grain boundaries. For (a) $0.15 \mathrm{C}$, (b) $0.25 \mathrm{C}$ and (c) $0.4 \mathrm{C}$ samples, these boundaries are visible because of pre-eutectoid $\alpha$-ferrite phase precipitating on the $\gamma$ grain boundary. For (d) $0.45 \mathrm{C}$ sample, the grain boundaries were highlighted by white color lines for visual aid. 
(a)

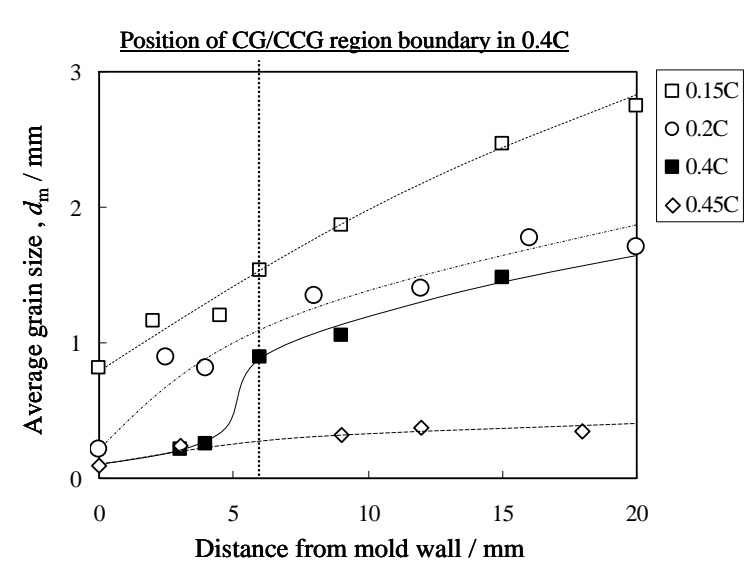

(b)

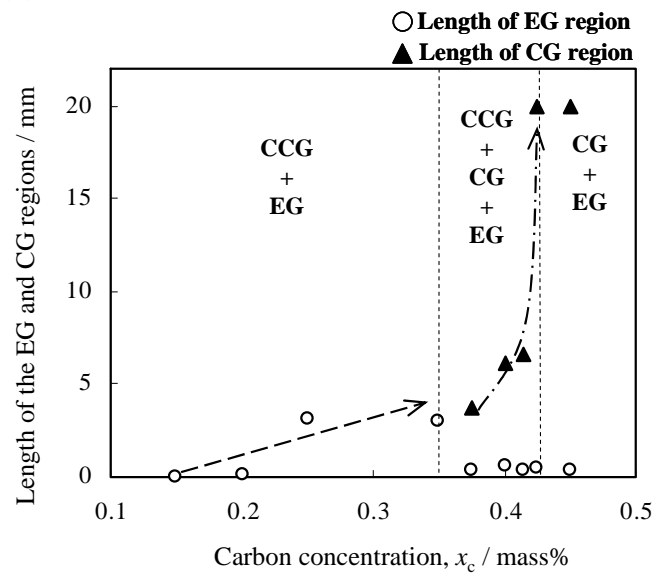

(c)

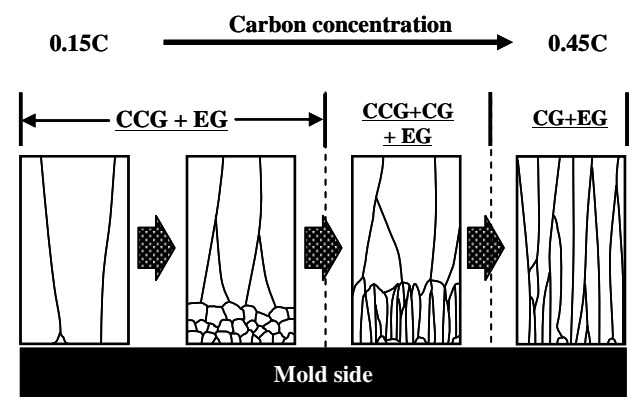

Fig. 2. (a) Relationship between the distance from the copper mold and average grain size in samples. (b) Effect of the carbon concentration on the length of EG and CG regions. (c) Schematic illustration of the variation of as-cast $\gamma$ structures with respect to the carbon concentration. 
(a)

(i)

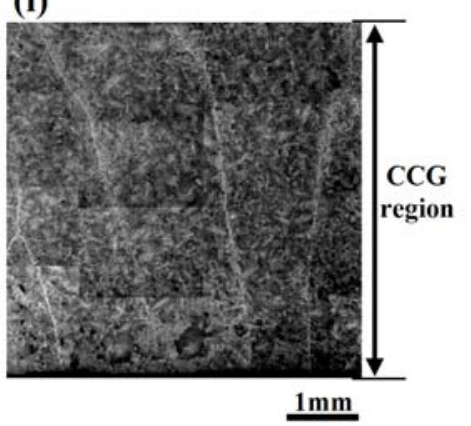

(ii)

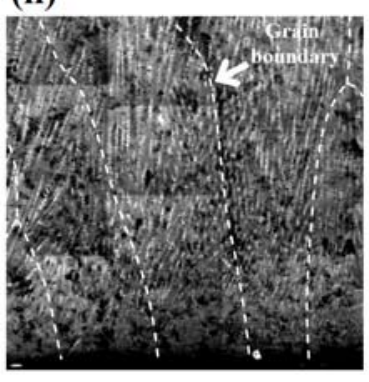

(b)

(i)

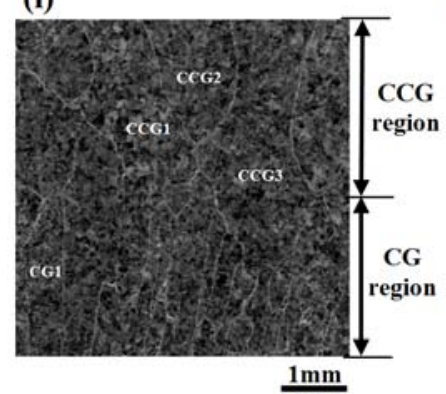

(ii)

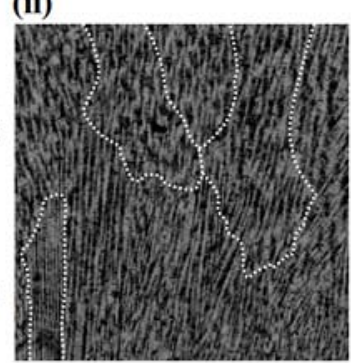

(iii)

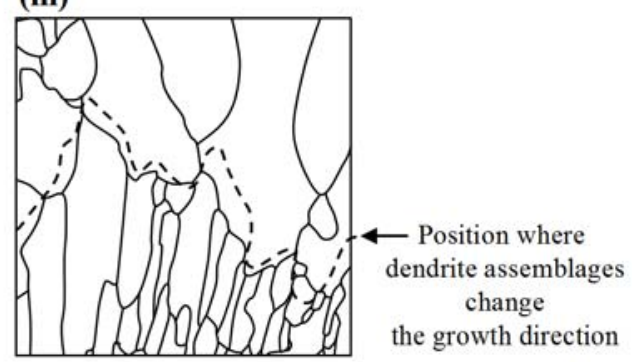

Fig. 3. Comparisons between the as-cast $\gamma$ grain structure and the dendrite structure. (a)-(i) CCG structure in 0.15C sample. (a)-(ii) Dendrite structure in the same region of Fig. 3(a)-(i). (b)-(i) $\gamma$ grain structure in the vicinity of boundary between CG and CCG region in 0.4C sample. (b)-(ii) Dendrite structure in the same region of Fig. 3(b)-(i). (b)-(iii) Trace of the as-cast $\gamma$ grain boundary with the dashed line showing a boundary where dendrite assemblages change their growth directions. The bottom and upper sides correspond to the bottom side and the top side of the ingot, respectively. 


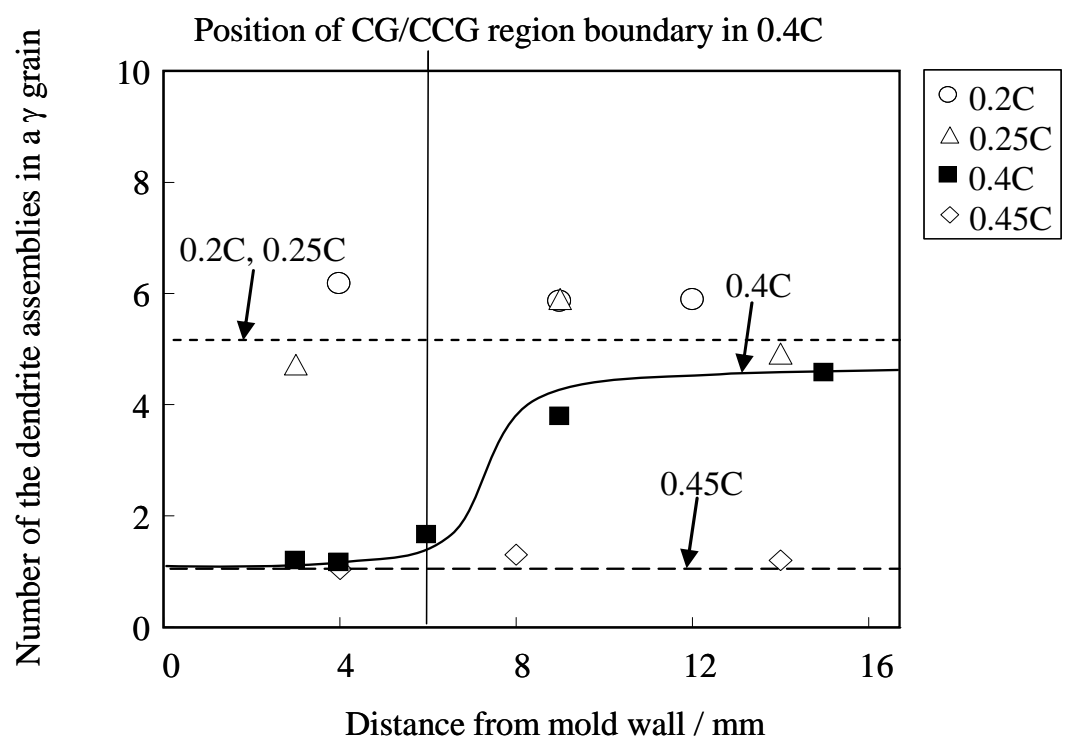

Fig. 4. Relationships between the average number of dendrite assemblages in a $\gamma$ grain and the distance from the copper mold. 
(a)

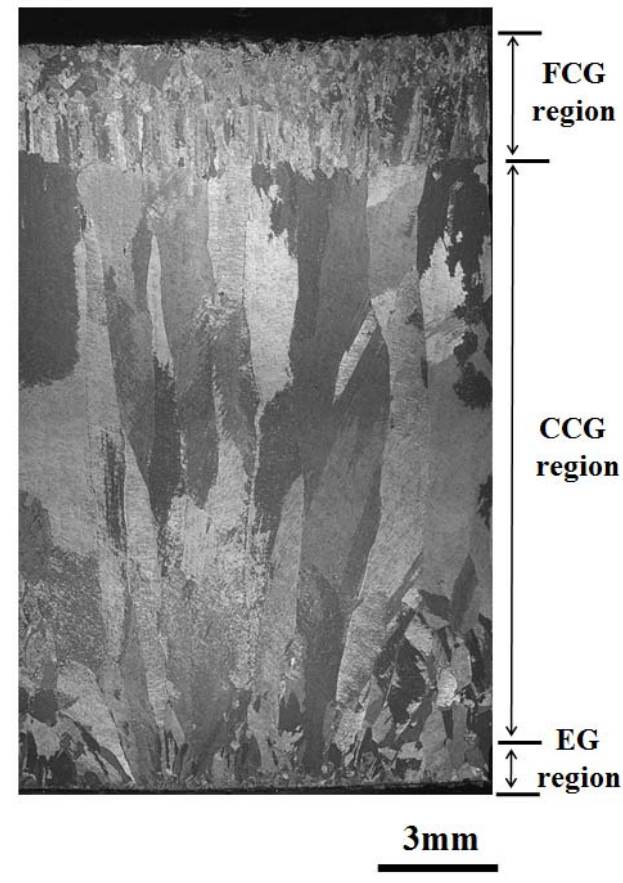

(c)

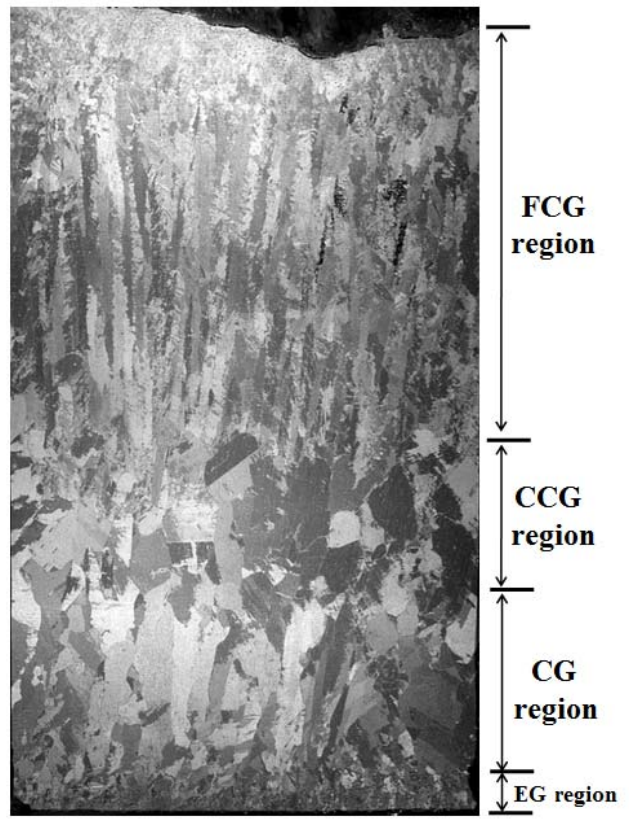

(b)

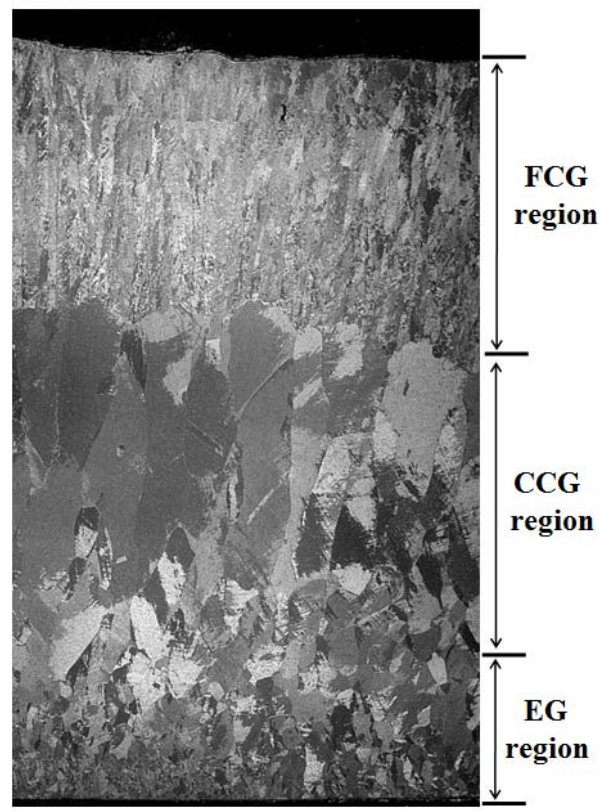

(d)

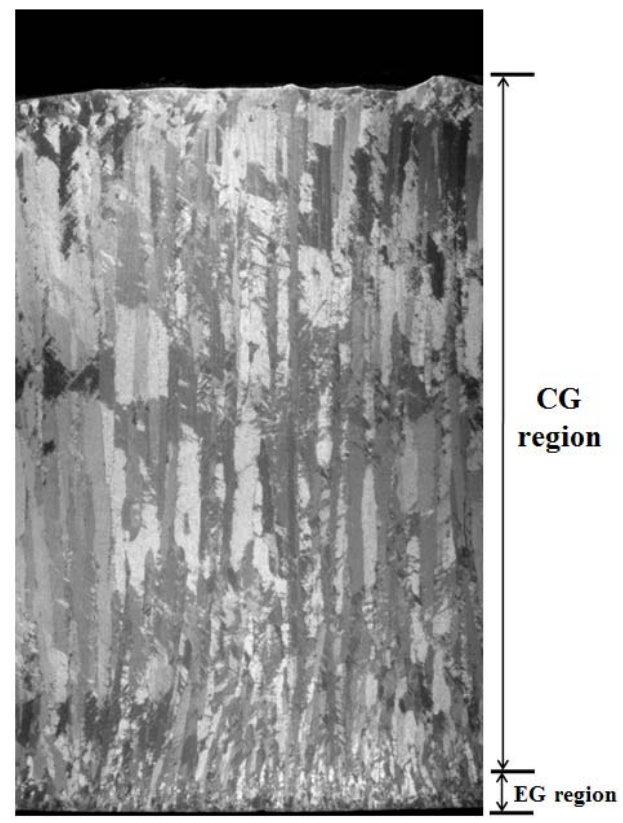

Fig. 5. Micrographs of (a)0.2C, (b)0.35C, (c)0.4C and (d)0.45C samples quenched at 30s after casting. 


\section{(b)}
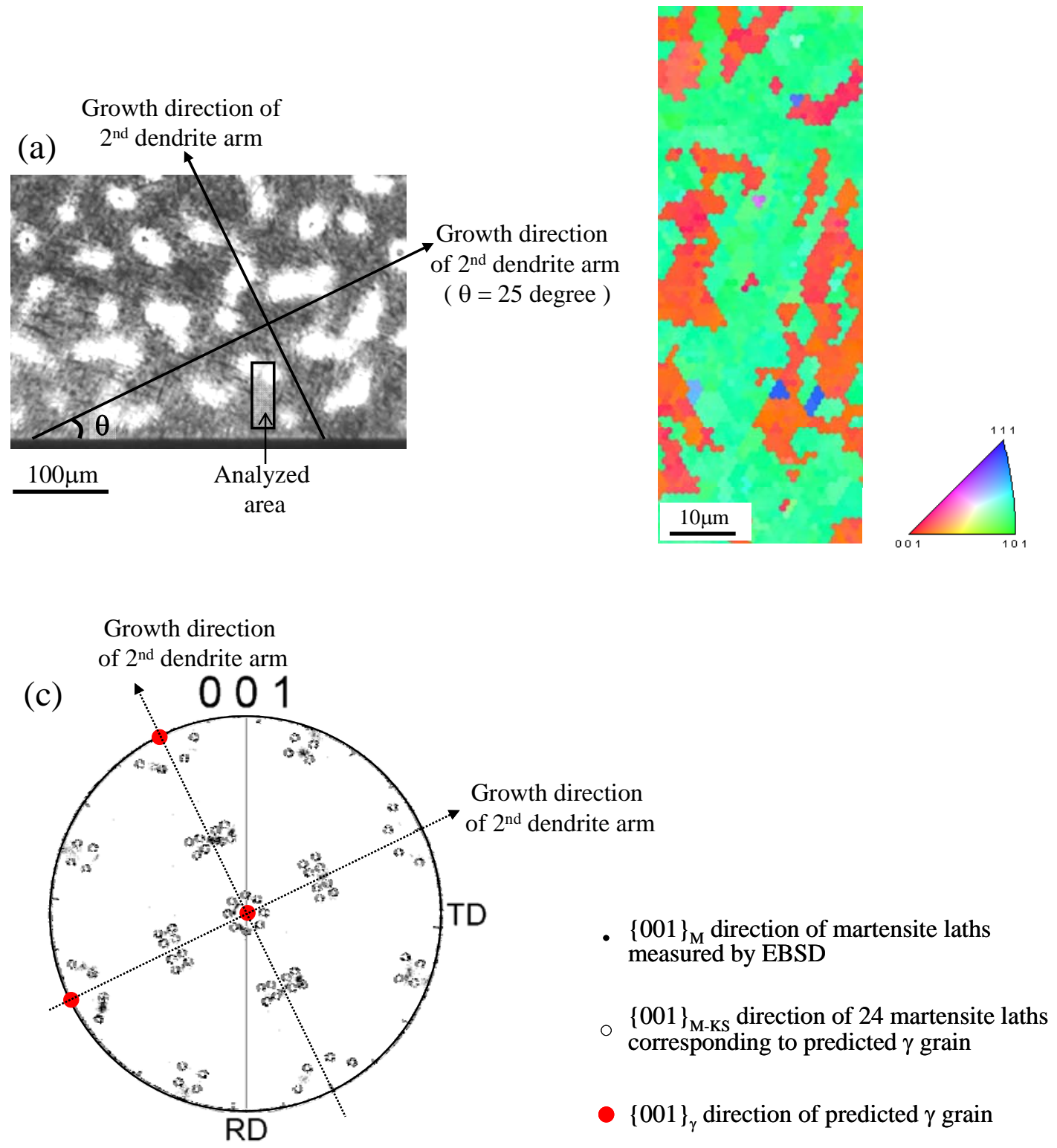

Fig. 6. Crystallographic analysis of martensite lath structure in a CG grain in $0.4 \mathrm{C}$ sample. (a)Dendrite structure in CG region of $0.4 \mathrm{C}$ sample quenched at 30 s after casting. The sample was sectioned at the height of $4 \mathrm{~mm}$ parallel to the bottom of the ingot. (b)IPF map of the rectangle shaped analyzed area in Fig. 6(a). (c) $\{001\}_{M}$ pole figure in the analyzed area in Fig. 6(a). $\{001\}_{\gamma}$ direction of prior $\gamma$ grain was determined by the correspondence of the $\{001\}_{\mathrm{M}}$ direction of measured martensite laths with the $\{001\}_{\mathrm{M}-\mathrm{KS}}$ direction of possible 24 variants of martensite laths, which was predicted by the K-S orientation relationship. 


\section{(b)}
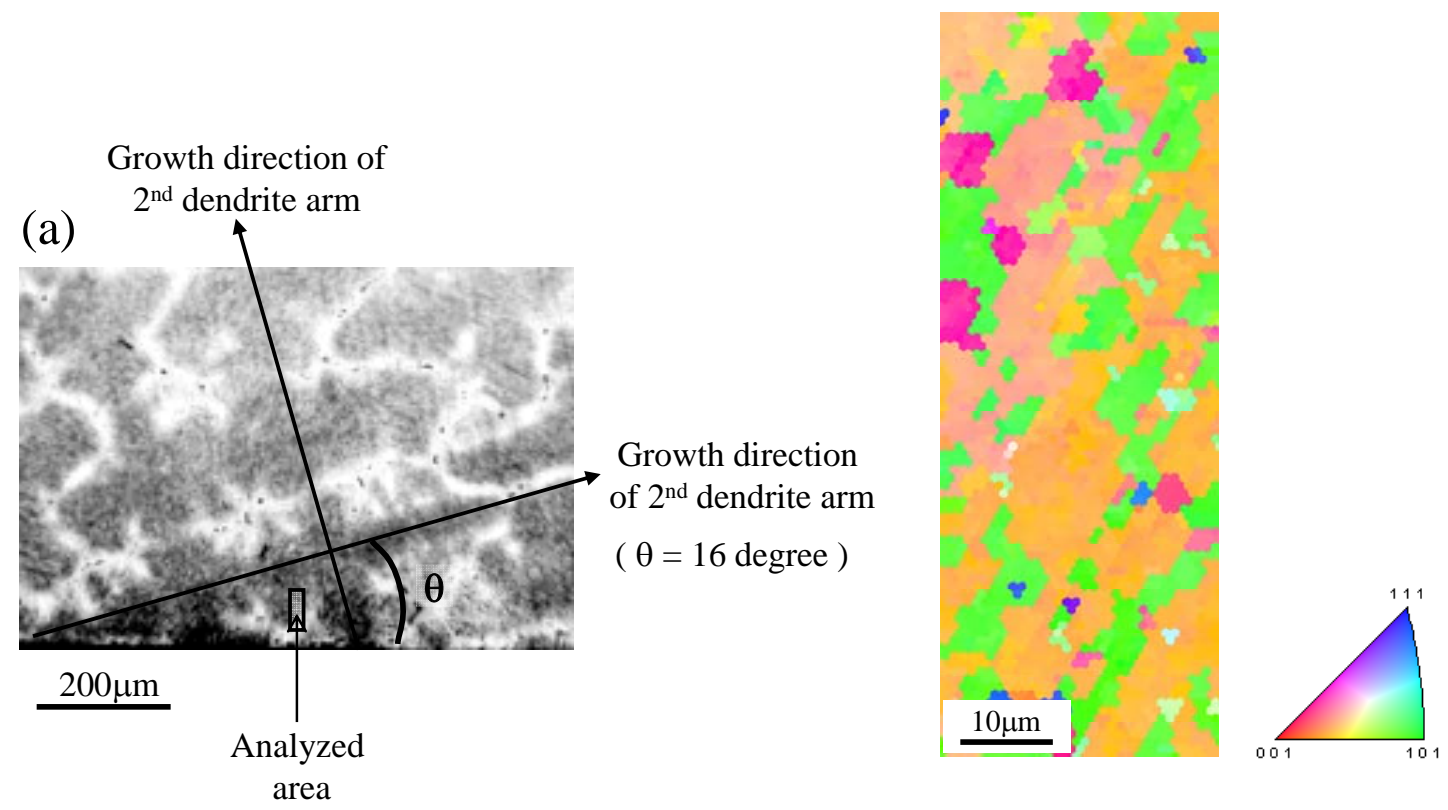

Growth direction of $2^{\text {nd }}$ dendrite arm

(c)

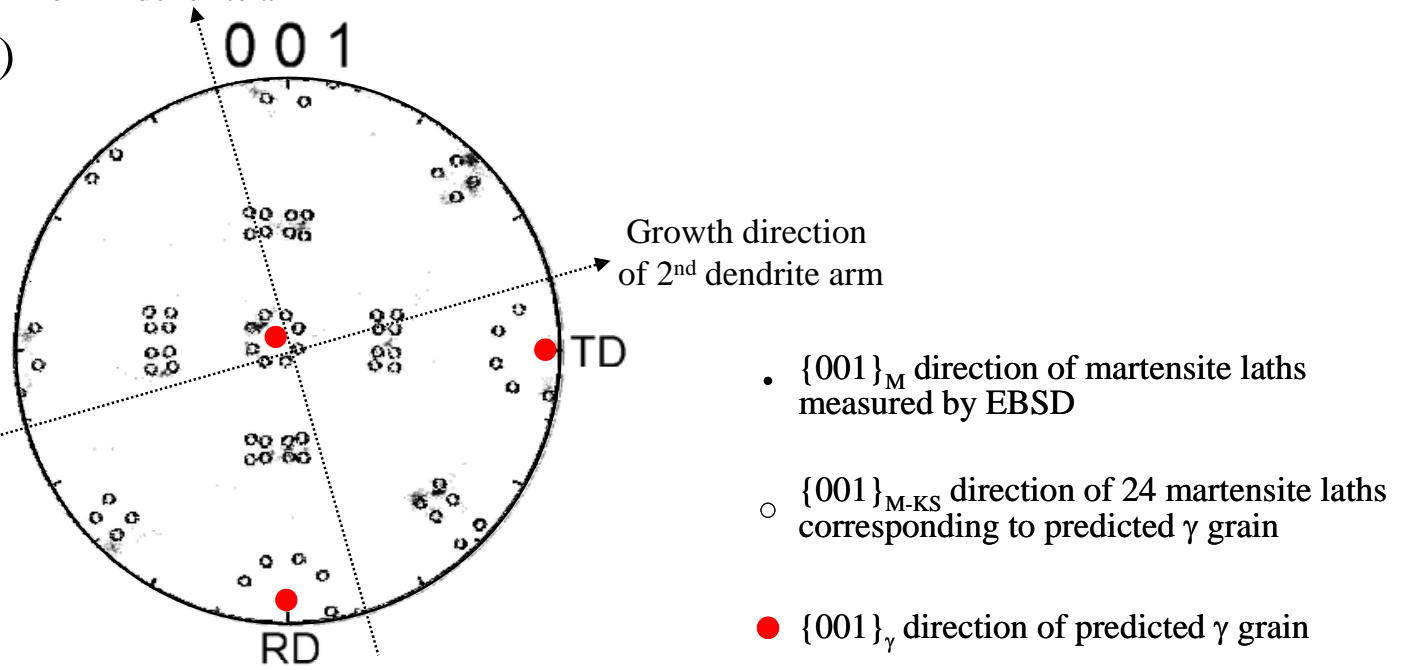

Fig. 7. Crystallographic analysis of martensite lath structure in a $\gamma$ grain of FCG in $0.4 \mathrm{C}$ sample. (a)The dendrite structure in FCG region of $0.4 \mathrm{C}$ sample quenched at 30s after casting. The sample was sectioned at the height of $10 \mathrm{~mm}$ parallel to the bottom of the ingot. (b)IPF map of the rectangle shaped analyzed area in Fig. 7(a). (c) $\{001\}_{M}$ pole figure in the analyzed area in Fig. 7(a). \{001 $\}_{\gamma}$ direction of prior $\gamma$ grain was determined by the correspondence of the $\{001\}_{\mathrm{M}}$ direction of measured martensite laths with the $\{001\}_{\mathrm{M}-\mathrm{KS}}$ direction of possible 24 variants of martensite laths, which was predicted by the K-S orientation relationship. 


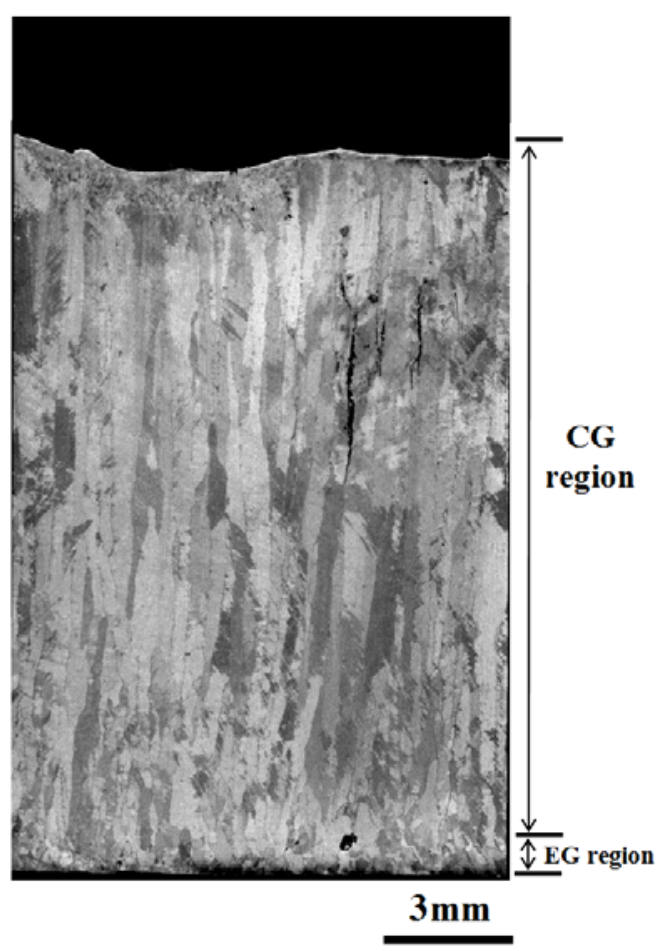

Fig. 8. Micrograph of 0.7C sample quenched at 30s after casting. 


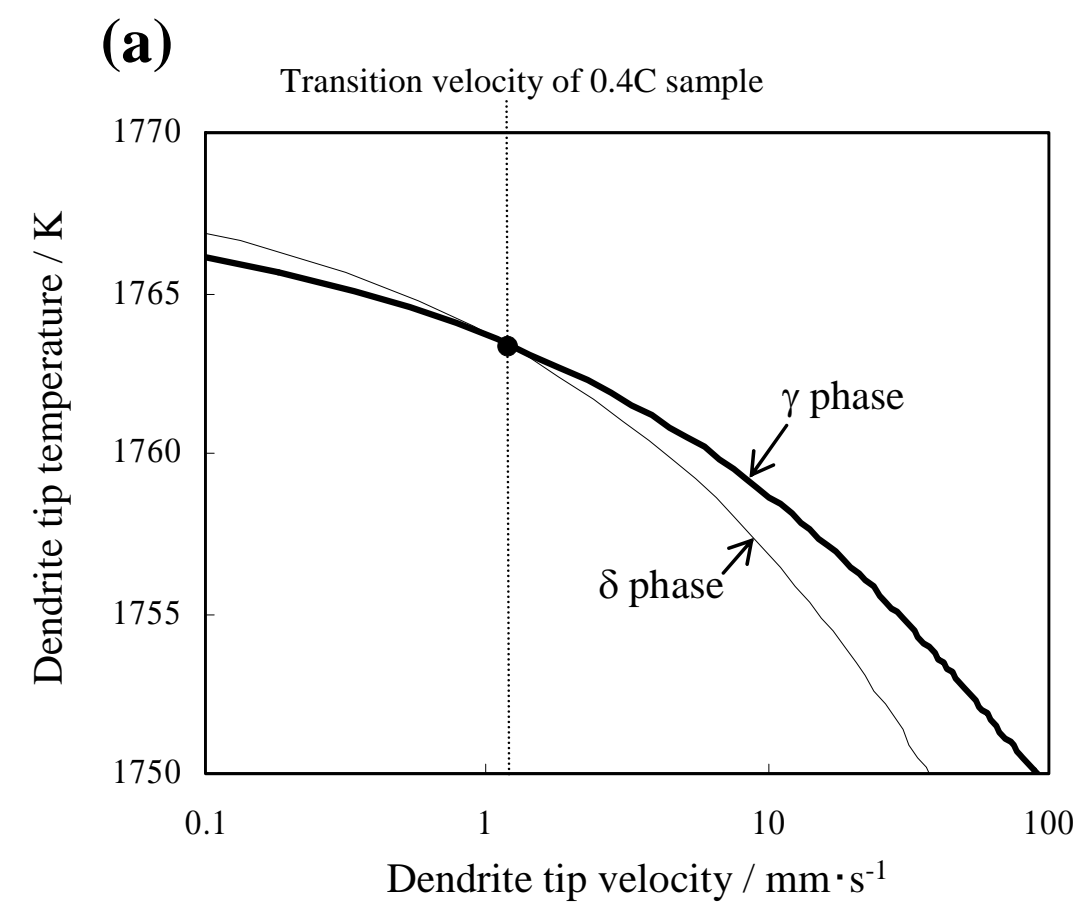

(b)

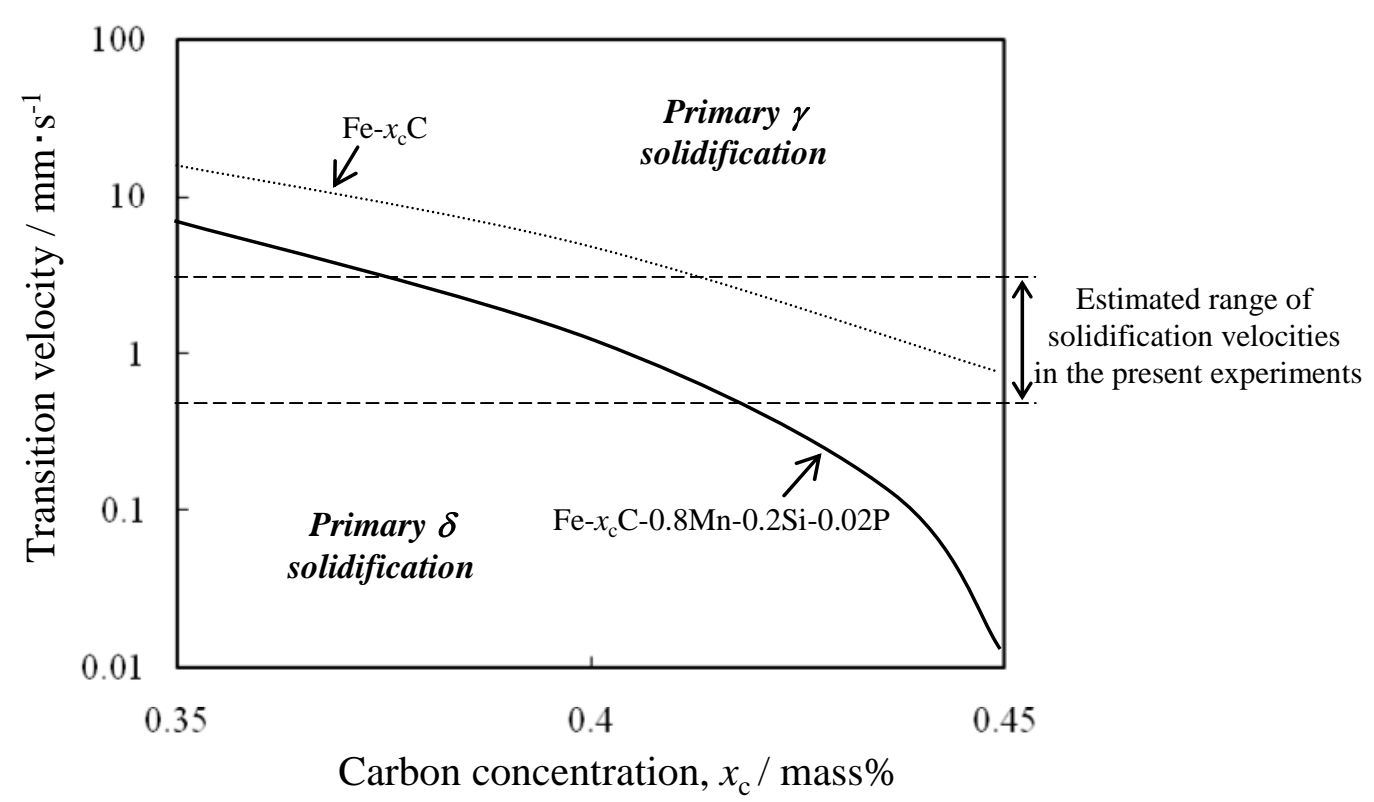

Fig. 9. Calculation results for the transition of primary solidification phase based on KGT model. (a)Relationship between dendrite tip velocity and tip temperature.

(b)Effect of the carbon concentration on the transition velocity between $\delta$ and $\gamma$ phases. 